\title{
Prohibido leer: la censura en la literatura infantil y juvenil desde el siglo xx hasta nuestros días
}

\section{Forbidden to Read: Censorship in Children's and Youth Literature from the Twentieth Century to the Present Days}

\author{
María Belen Rojas Chávez \\ Universidad Nacional Autónoma de México \\ Facultad de Filosofía y Letras \\ belenrc517@gmail.com
}

Del 17 al 26 de septiembre de 2019 se llevó a cabo en el Instituto de Investigaciones Filológicas el curso Prohibido Leer: La censura en la literatura infantil y juvenil desde el siglo $\mathrm{XX}$ hasta nuestros días, impartido por el doctor César Sánchez Ortiz de la Universidad de Castilla-La Mancha (España). El curso tuvo como objetivo brindar un acercamiento general sobre la historia de la Literatura Infantil y Juvenil (LIJ) en España y Latinoamérica, para reflexionar cuestiones relacionadas con la censura política y social que esta ha experimentado desde el siglo xx hasta la actualidad.

El curso constó de siete sesiones de tres horas cada una. En la primera, el doctor Sánchez Ortiz explicó su concepto de LIJ y la caracterización por la crítica, basó su exposición en los estudios que la Universidad de Castilla-La Mancha ha desarrollado durante los últimos 20 años. En esta revisión, destacó la figura de Pedro César Cerrillo, como el principal teórico y difusor de la LIJ en España. En la segunda sesión, analizó las características de la LIJ, como los personajes, la técnica y la estructura.

La tercera sesión estuvo a cargo de la doctora Arantxa Sanz Tejada, quien hizo una interesante revisión de esta literatura y su vínculo con la mediación lectora en el siglo XXI. La doctora Sanz profundizó en el concepto de litera- 
tura juvenil y sus nuevos soportes digitales. Por ejemplo, la importancia que ha cobrado durante los últimos años la herramienta electrónica booktube, entendida como una comunidad dentro de YouTube en la que se suben videos que giran en torno a los libros y la lectura. Algunos booktubers mencionados fueron: Javier Ruescas, Alberto Villarreal y Andreo Rowling.

El tema de la censura en la LIJ se planteó en la cuarta sesión. El doctor Sánchez Ortiz inició su presentación explicando a qué nos referimos cuando hablamos de censura en la LIJ y qué implicaciones tiene dentro del mercado cultural, así como las repercusiones en la mediación y la lectura individual y colectiva. Señaló que existen dos tipos de censura: las censuras evidentes, que, como su nombre lo dice, son totalmente explícitas, y las censuras soterradas, aquellas que tienen sustento en el propio concepto de 'infancia' y que no expresan abiertamente una prohibición; estas últimas son, por lo general, ejercidas por maestros y familiares. Las censuras tienen un papel fundamental en la LIJ, porque son los mecanismos con los cuales se decide qué es lo que deben leer los niños y qué no.

Durante las siguientes sesiones se estudiaron las censuras en la España franquista, en México y en Latinoamérica, en países como Argentina, Colombia, Cuba, Guatemala y Venezuela. Las censuras ejercidas durante las dictaduras de estos países fueron el motivo de prohibición de libros que podían atentar, según el régimen, contra la moral, la religión o la política; otros se autorizaban con objeciones o se permitían, pero con comentarios negativos de los censores oficiales. En el caso de la España franquista, algunas obras prohibidas fueron: Blanca Nieves, Jane Eyre, los cuentos de los hermanos Grimm y Charles Dickens.

La sesión sobre la censura en México estuvo a cargo de las doctoras María Teresa Miaja y Angélica Jiménez, quienes presentaron su estudio de caso sobre los Libros de Texto Gratuitos de la Secretaría de Educación Pública y su importancia en la difusión de la literatura a partir de la inclusión de una novedosa diversidad de temas. Sobre la LIJ censurada en México, las investigadoras apuntaron que algunos libros fueron excluidos de las bibliotecas públicas y las escuelas debido a los temas que abordan, entre los que destacan: el aborto, el divorcio, la prostitución, las enfermedades, la perspectiva de género, la discriminación, las razas, la trata de personas, la migración y el narcotráfico. Ejemplos de títulos censurados en México son: Cien corridos: Alma de la canción mexicana, de Mario Arturo Ramos; Aura, de Carlos Fuentes y La peor señora del mundo, de Francisco Hinojosa. 
En síntesis, el curso permitió a los asistentes adentrarse en una literatura que muchas veces se considera como subordinada en el canon literario. En palabras del doctor César Sánchez Ortiz, la LIJ no debe ser segregada de la literatura, sino que hay que considerarla una literatura independiente, con un esquema de recepción y mediación distinto. Las censuras en la LIJ son un mecanismo de control que los gobiernos, las instituciones y las familias utilizan para restringir la lectura, con el objetivo de "salvaguardar la inocencia" de los niños y los jóvenes; en realidad, concebida a partir de una construcción cultural producto de cada sociedad en particular.

\section{María Belen Rojas Chávez}

Estudiante de la licenciatura en Lengua y Literaturas Hispánicas en la Facultad de Filosofía y Letras (UNAM). Interesada en la literatura mexicana del siglo XIX, la literatura fantástica hispanoamericana, la literatura infantil y juvenil y la edición crítica de textos. 